\title{
A cautionary note regarding long-term sequelae of biologic glue
}

\author{
Dumbor L. Ngaage, FRCS (C-Th), ${ }^{a}$ William D. Edwards, MD, ${ }^{b}$ Malcolm R. Bell, MD, ${ }^{c}$ and Thoralf M. Sundt, MD, ${ }^{a}$ \\ Rochester, Minn.
}

$\mathrm{P}$

ostoperative hemorrhage remains a significant cause of mortality and morbidity after repair of acute aortic dissection. Accordingly, there has been great interest in the development and application of biologic hemostatic tissue sealants for use during this and other aortic surgical procedures. ${ }^{1}$ Among these agents, BioGlue (Cryolife, Inc, Kennesaw, Ga) appears remarkably effective and has rapidly gained wide acceptance. ${ }^{1,2}$ However, because it is composed of $45 \%$ (wt/vol) purified bovine albumin and $10 \%(\mathrm{wt} / \mathrm{vol})$ glutaraldehyde in a $4: 1$ ratio, we have been concerned that it might not be completely innocuous. We have recently encountered a case of late anastomotic pseudoaneurysm potentially related to the use of BioGlue.

\section{Clinical Summary}

During cardiologic evaluation of recurrent atrial flutter, a 76-yearold man was found to have a pseudoaneurysm of the ascending aorta. Two years previously, he had an acute type A dissection, for which he underwent graft replacement of the ascending aorta and hemiarch, as well as bioprosthetic aortic valve replacement, at another institution. In addition, he had a stable $3.1-\mathrm{cm}$ abdominal aortic aneurysm, chronic obstructive pulmonary disease, history of seizure disorder, and recurrent atrial tachyarrhythmia for which catheter ablation and electrical cardioversion had been performed.

Transthoracic echocardiography demonstrated normal left ventricular (LV) function, mild-to-moderate mitral regurgitation, moderate aortic periprosthetic regurgitation, grade $3 / 4 \mathrm{LV}$ diastolic dysfunction consistent with severely increased LV filling pressure, and a dilated ascending aorta. Computed tomography with 3dimensional reconstruction performed to evaluate the aorta (Figure 1) demonstrated an ascending aortic pseudoaneurysm, although the entry site could not be identified. Coronary angiography and aortography, respectively, revealed normal coronary arteries and a pseudoaneurysm of the ascending aorta with what appeared to be entry sites both proximally and distally.

Repair of the pseudoaneurysm was undertaken through a repeat median sternotomy with femorofemoral cardiopulmonary bypass and a transthoracic LV vent. Because of concern that the pseudoaneurysm would be entered, re-entry was undertaken only after profound cooling to permit hypothermic circulatory arrest, if nec-

From the Divisions of Cardiovascular Surgery, ${ }^{\mathrm{a}}$ Anatomic Pathology, ${ }^{\mathrm{b}}$ and Cardiovascular Diseases, ${ }^{\mathrm{c}}$ Mayo Clinic, Rochester, Minn.

Received for publication July 16, 2004; accepted for publication July 21, 2004.

Address for reprints: Thoralf M. Sundt, MD, Mayo Clinic, 200 First St SW, Rochester, MN 55905 (E-mail: sundt.thoralf@mayo.edu).

J Thorac Cardiovasc Surg 2005;129:937-8

$0022-5223 / \$ 30.00$

Copyright (C) 2005 by The American Association for Thoracic Surgery

doi:10.1016/j.jtcvs.2004.07.046 essary. Adhesions surrounding the aortic graft and forming the wall of the pseudoaneurysm were extraordinarily dense.

Both proximal and distal suture lines were almost circumferentially disrupted, and the aortic cuff appeared soft and friable. Persistent concretions of BioGlue were identified between the aortic layers. The previous graft was excised in its entirety, and the cuff of the native aortic tissue was debrided of all visible traces of BioGlue. Microscopy of resected aortic tissue revealed focal adventitial fibrosis, degenerating thrombus, amorphous biologic glue, and focal acute and chronic nongranulomatous inflammation (Figure 2).

An aortic valve periprosthetic leak was repaired, and the ascending aorta and hemiarch were rereplaced with a synthetic tube graft. The patient made a satisfactory recovery and was discharged on the 10th postoperative day.

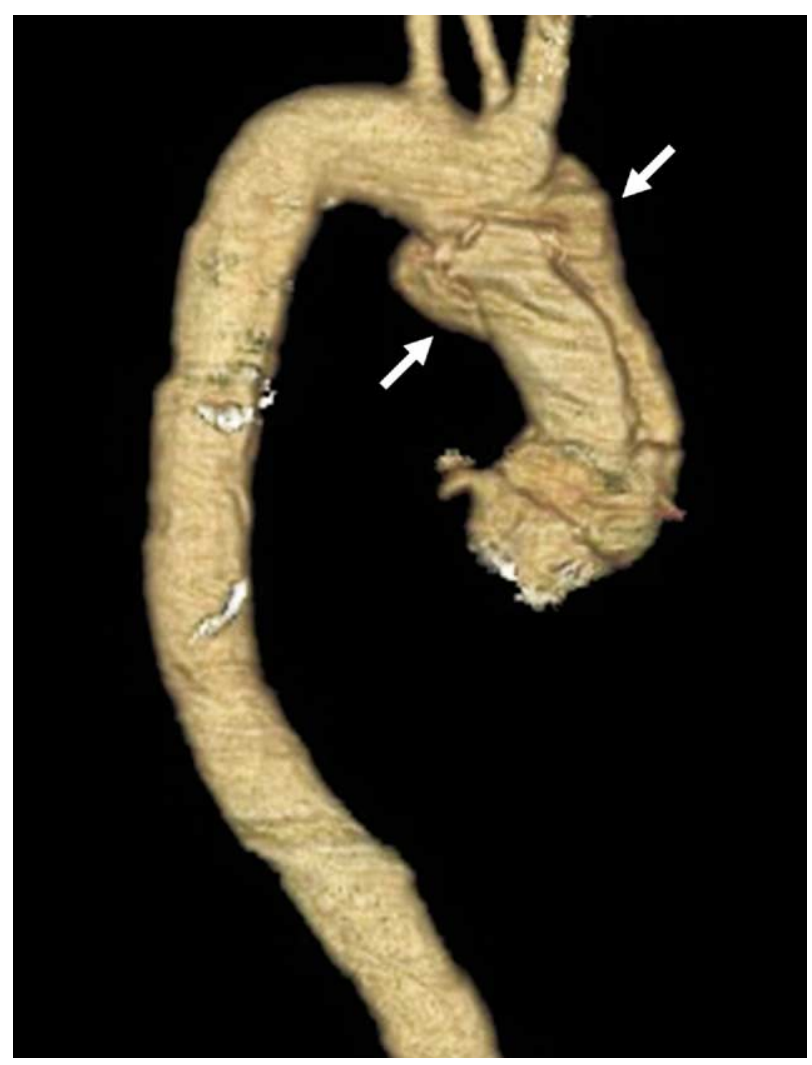

Figure 1. Computed tomographic scan with 3-dimensional reconstruction of the aorta demonstrating pseudoaneurysm around the ascending aortic Dacron tube graft (posterior view). 

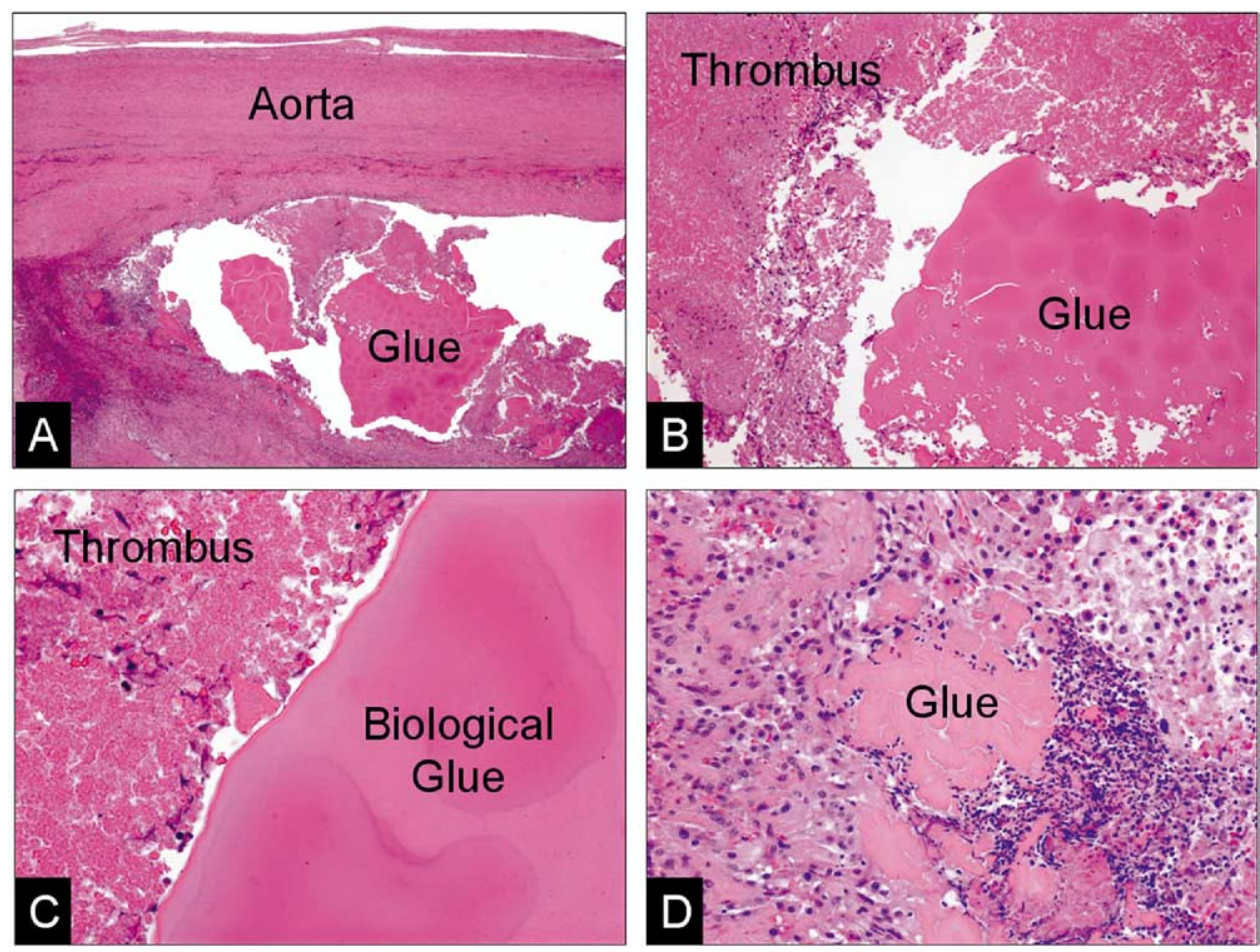

Figure 2. Photomicrographs of aorta and biologic glue. A, Low-power view showing aortic wall and expansion of adventitia by glue and tissue reaction. B and C, Biologic glue and adjacent platelet-fibrin thrombus. D, Focal intense inflammatory response to glue, with infiltrates of lymphocytes and macrophages. (Hematoxylin and eosin; Original magnification: A, 20x; B, 100x; C, 200×; D, 400×.)

\section{Discussion}

Biologic adhesive hemostatic sealants facilitate cardiac surgical procedures and are particularly useful in cases in which the proclivity for bleeding is high. ${ }^{1}$ Various biologic glues have been used in cardiac surgery for more than 2 decades. ${ }^{2}$ Despite initial enthusiasm, late complications directly related to their use have become apparent with time. ${ }^{3}$

Our experience raises concern about the potentially harmful effects of BioGlue to local tissue. It has been our anecdotal observation during reoperation on patients in whom large quantities of BioGlue appear to have been used that the substance persists and that surrounding tissues are soft and friable. The results of histologic study in the current case demonstrate an ongoing local inflammatory process 2 years after application, indicating that BioGlue might retard normal healing. This substance has previously been shown to impair tissue growth and cause stricture formation in some circumstances ${ }^{4}$ and has been shown to lead to tissue necrosis. ${ }^{5}$ These changes in structural integrity might weaken the tissues and predispose to late complications, such as pseudoaneurysm formation, as has been previously suggested. ${ }^{6}$

Prior experience with other biologic glues ${ }^{3,5}$ might now evoke a sense of déjà vu with BioGlue. There is no question that the benefits of such agents in controlling blood loss in cardiac surgery might be truly life-saving in some circumstances. Nevertheless, their use should be parsimonious, and glues should not be considered substitutes for sutures and fastidious surgical hemostasis.

\section{References}

1. Coselli JS, Bavaria JE, Fehrenbacher J, Stowe CL, Macheers SK, Gundry SR. Prospective randomized study of a protein-based tissue adhesive used as a hemostatic and structural adjunct in cardiac and vascular anastomotic repair procedures. J Am Coll Surg. 2003;197: 243-52.

2. Guilmet D, Bachet J, Goudot B, et al. Use of biological glue in acute aortic dissection. Preliminary clinical results with a new surgical technique. J Thorac Cardiovasc Surg. 1979;77:516-21.

3. Bingley JA, Gardner MA, Stafford EG, et al. Late complications of tissue glues in aortic surgery. Ann Thorac Surg. 2000;69:1764-8.

4. LeMaire SA, Schmittling ZC, Coselli JS, et al. BioGlue surgical adhesive impairs aortic growth and causes anastomotic strictures. Ann Thorac Surg. 2002;73:1500-5.

5. Kazui T, Washiyama N, Bashar AH, et al. Role of biologic glue repair of proximal aortic dissection in the development of early and midterm redissection of the aortic root. Ann Thorac Surg. 2001;72:509-14.

6. Downing SW. What are the risks of using biologic glues? [letter]. Ann Thorac Surg. 2003;75:1063. 